\title{
Determination of Optimal Temperature for Production of Quality Eri Silkworm Cocoon and Seed
}

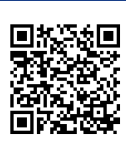

\author{
Endale Hailu ${ }^{1,2,3}$, Yuehua Zhang ${ }^{1,2 *}$ and Workneh Ayalew ${ }^{3 *}$ \\ ${ }^{1}$ Jiangsu University of Science and Technology, China \\ ${ }^{2}$ Sericultural Research Institute, Chinese Academy of Agricultural Sciences, China \\ ${ }^{3}$ ICIPE Ethiopia YESH Project, Ethiopia
}

Submission: August 03, 2018, Published: August 21, 2018

"Corresponding author: Yuehua Zhang, Jiangsu University of Science and Technology, Sericultural Research Institute, Chinese Academy of Agricultural Sciences, Zhenjiang Jiangsu 212003, China, Tel: 8618796089725; Email: cyszyh@163.com

*Workneh Ayalew, ICIPE Ethiopia Young Entrepreneurs in Silk and Honey (YESH) Project, Addis Ababa, Ethiopia, Email: wayalew@icipe.org

\begin{abstract}
Agro-ecological variables play a crucial role in performance of eri silkworm cocoon production and seed selection. The main intention of the experiment was to evaluate effects of temperature on cocoon, pupa and cocoon shell weight to identify an optimum temperature for improved silk production and quality seed preparation. Four filial generations of yellow plain Eri silkworm types were used to study the effects of temperature on cocoon production at Bere Sericulture Production PLC in Arba Minch, Ethiopia. Four temperature gradients, $20^{\circ} \mathrm{C}, 25^{\circ} \mathrm{C}, 30^{\circ} \mathrm{C}$ and $35^{\circ} \mathrm{C}$, were used with ten replications. The cocoon weight scores and egg hatchability data were subjected to statistical analysis at $\mathrm{P}<0.05$ using $\mathrm{R}$ version 3.4.3. Mean separation was conducted using least significant difference (LSD) at $\mathrm{P}<0.05$ using the package "agricolae" in R. It was observed that temperature gradient significantly affected $(\mathrm{P}<0.001)$ cocoon, pupa, cocoon shell weight, egg number and hatchability of the eggs. The potential egg hatchability and cocoon production were obtained at $25^{\circ} \mathrm{C}$. The promising production can be obtained at temperature range of $25-30^{\circ} \mathrm{C}$. Filial generations had no effect on pupa, cocoon shell weight, egg number and hatchability of the eggs, except on cocoon $(\mathrm{P}<0.05)$. The present study therefore suggests that the ideal eri silkworm rearing temperature ranged from $23^{\circ} \mathrm{C}$ up to $30^{\circ} \mathrm{C}$
\end{abstract}

Keywords: Eri silkworm cocoon; Eri silkworm seed; Temperature

Abbreviations: LSD: Least Significant Difference; FG: Filial Generations; RCBD: Completely Randomized Block Design; FG: Filial Generations;

\section{Introduction}

Silk production was first introduced to Ethiopia by Italians in 1936. It was restarted almost after six decades by Melkassa Agricultural Research Center, which has been coordinating the silk production activity in the country [1]. Since then, small scale trials and demonstrations of silkworm farming were conducted in various parts of the country. Although both Mulberry and Eri silkworm farming have been promoted, eri silkworm farming has become increasingly more popular in Ethiopia [2], especially in Arba Minch and Meirab Abaya districts of Gamo Gofa Zone, Ethiopia [2,3].

Bere Silk Production PLC is the largest commercial silk producer and processor in the country. It also purchases cocoons from smallholder farmers, while supplying them with silkworm seeds. The company works with both individual smallholder farmers and farmers' groups to develop the local sericulture industry. In particular, it has been supplying the farmers with seeds of eri silkworms and castor beans, as well as deliver technical advisory services. Farmers, in turn, supply dry silk cocoons to the Company, which then processes the cocoons and sells to other companies [4].

The eri silkworm (Philosamia cynthia ricini) feeds mainly on leaves of castor bean, but also on a wide range of plants such as cassava (tapioca), kissaru, payam, barpat, papaya, jatropha and barkesseru. The word 'Eri' is derived from the word 'era' which means castor. The insect is multi-voltine and completes 5 to 6 generations or crops peryear [1,5-8]. The life cycle of eri-silkworm has four stages: egg, larva with five instars, pupa encased in cocoon and adult moth. The entire life cycle takes 44 days in summer and 85 days in winter [9].

Mechanical coupling is not necessary for eri moths because they have a natural affiliation for self-coupling. For mating, 23$24{ }^{\circ} \mathrm{C}$ optimum temperature and $75-80 \%$ relative humidity are required. Even though Behura and Panda in 1978 as cited in [9] reported that 4 hours of mating is adequate for normal oviposition, 8 to 10 hours of coupling and decoupling may be required with mating taking place an hour after moth emergence. 
The appropriate temperature and humidity for egg laying by eri moths are $25-26^{\circ} \mathrm{C}$ and $80-90 \%$, respectively, under a semi dark environment and allow the moths to lay eggs for a period of 2-3 days. On average a single eri moth can lay 400-450 eggs during this period, depending on type of feeds, suitability of egg laying devices and seasonal climatic variables [10].

The phenotypic expression of silkworm genotype in the form of cocoon, shell and cocoon shell weights are also influenced by environmental factors such as temperature. The optimum temperature for growth of young stage eri silkworms is about $26-28{ }^{\circ} \mathrm{C}$, with relative humidity of $85-90 \%$, whereas for later stage worms slightly cooler temperatures of $24-26^{\circ} \mathrm{C}$ and relative humidity of $70-80 \%$ are required $[7,11]$. Whereas, the ambient temperature for growth of eri silkworms can range from 20 to 40 ${ }^{\circ} \mathrm{C}$ [12]. Regardless of the location, profitable silkworm rearing requires suitable temperature, relative humidity, light intensity, soil type and low rainfall. Because of lack of specific research information on optimum temperature for egg laying and cocoon production at Arba Minch area, this study evaluated the effect of temperature ranges on egg and cocoon productions to fill the prevailing gap.

\section{Materials and methods}

This experiment was conducted between September 2016 and June 2017 at the facilities of Bere Sericulture Production PLC in Arba Minch, located at $6.0206^{\circ} \mathrm{N}$ latitude and $37.5641^{\circ}$ E longitude. The annual maximum average temperature is 30.57 ${ }^{\circ} \mathrm{C}$ and annual minimum average temperature is $23.51{ }^{\circ} \mathrm{C}$ [13]. Yellow plain eri-silkworm (P. c. ricini) variety sourced from the Melkassa Agriculture Research Center of the Ethiopian Institute of Agricultural Research was used in this experiment. The erisilkworms were consecutively self-mated at optimum growth conditions to produce four filial generations (FG) before starting the temperature gradient experiment. Then ten days old fourteen cocoons were selected as parental stock and were kept at $25 \pm 2{ }^{\circ} \mathrm{C}$ temperature and standard humidity ( $80 \pm 5 \%$ Relative Humidity) for conducting the experiment adopted [14].

On 16 September six female adult moths were exposed to mate, decoupled after 10 hours of mating and kept in a dark egg laying box for three days. On the fourth day, eggs were collected following the procedure Sarmah et al. [10]. On the fifth day the eggs were disinfected by dipping for 5 minutes in a solution of seven drops of bleaching liquid in one litre of water and washed with tap water for 25 minutes or in a $2 \%$ formalin solution for 30 seconds and then in running water till the traces of formalin were completely removed, and dried under shade for 5-6 hours, during which the eggs were counted. The procedure was followed for each of the four filial generations of the experiment.

A completely randomized block design (RCBD) was fitted to the data, in which four temperature values were taken as the treatment variables and successive filial generations as blocks, by keeping other environmental variables similar, namely air humidity $80 \pm 5 \%$ quality and quantity of castor leaves, light hours, rearing space, general hygiene and conditions for cocoon production. The temperature treatments include a control (C) rearing temperature of $25 \pm 2{ }^{\circ} \mathrm{C}$ and three test temperatures of Treatment one (T1) of $20 \pm 2{ }^{\circ} \mathrm{C}$, Treatment two (T2) of $30 \pm 2{ }^{\circ} \mathrm{C}$ and Treatment three (T3) of $35 \pm 2{ }^{\circ} \mathrm{C}$. The four consecutive filial generations were observed from 10 September 2016, i.e. the first filial generation (F1) from 10 September to 28 October 2016, the second filial generation (F2) from 29 December 2016 to 16 February 2017; the third filial generation (F3) from 17 February to 01 April 2017, and the fourth filial generation (F4) from 02 April to 03 June 2017. Rearing appliances were cleaned, washed, sun-dried and disinfected with $2 \%$ formalin solution at the rate of $800 \mathrm{ml}$ per $\mathrm{m} 2$ following the protocol Rajan and Himantharaj [15]. The eggs used for the experiment were checked for being free from known diseases.

Wooden trays with dimension of $60 \mathrm{~cm}$ width, $90 \mathrm{~cm}$ length and $2.5 \mathrm{~cm}$ height were used to rear the silkworms from brushing until cocoon unwinding stages. Larval stage silkworms were fed on tender castor leaves four times a day until the 3rd instar and mature castor leaves were fed to the 4 th and 5 th instar larvae. The four feeding periods during the experiment were: morning from 8:00 - 8:30 AM, mid-day from 11:30 - 12:00 noon, after noon from 2:00 - 2:30PM and evening from 5:00 - 6:00PM. Before bed cleaning, fresh leaves in single layer were spread on top of the larvae in the feeding trays. The worms gradually crawled up to the leaves, and these were then transferred to newspaper covered beds to allow cleaning of the rearing trays. The litter, including manure, leftover feed and dead silkworms, was removed carefully and disposed away from rearing house. After completing feeding during late fifth instar, grown up worms at their ripened stage were picked and transferred to mountages, where the larvae stage turns to pupae stage. After spending eight days in the mountage, the pupae encased in cocoon were harvested. Observations on larval duration, larval mortality rate and four cocoon traits, namely cocoon weight, cocoon shell weight, pupa weight and silk ratio were recorded. Egg feasibility test was determined as the number of eggs per individual moth. Likewise, hatching percentage was recorded for each sample as the proportion of eggs laid and counted that hatched, i.e:

$$
\text { Hatchability }(\%)=\frac{\text { Hatched egg }}{\text { Total eggs counted }} \times 100
$$

Thermometer and hygrometer devices were set up in the four experimental rooms to monitor temperature and relative humidity and adjust with scheduled values for the respective treatments. During colder weather, the rearing room temperature was regulated by heating the rooms with local charcoal heaters to arrive at scheduled thermometer and hygrometer reading. During warmer periods windows and doors of experimental rooms were covered with wet cloth, and the floors were sprayed with water until the desired thermometer and hygrometer reading were achieved. Proper ventilation was ensured to avoid build-up of carbon dioxide and other gases emitted in this burning process. 
Smoking was controlled both inside and in the vicinity of the experimental rooms.

The data was analyzed using $\mathrm{R}$ package version 3.4.3. Significant statistical differences between means were tested at $5 \%$ level of significance using the least significant differences (LSD) in R using "agricolae" package.

\section{Results}

The results of study showed that eri silkworm growth performance measured as cocoon weight, pupa weight and shell weight, egg number and hatchability were significantly $(\mathrm{P}<0.001)$ influenced by variations in temperature. The highest cocoon yield was obtained when the rearing rooms were adjusted to 25 degree centigrade (Figure 1). Cocoon production significantly reduced at higher or lower temperature test values. Filial generations significantly affected this cocoon production at $\mathrm{P}<0.05$. This significant variation between the filial generations was brought about by the F3 and F4 generations (data not shown). The interaction between the temperature gradients and the filial generations had no effect on the cocoon production.

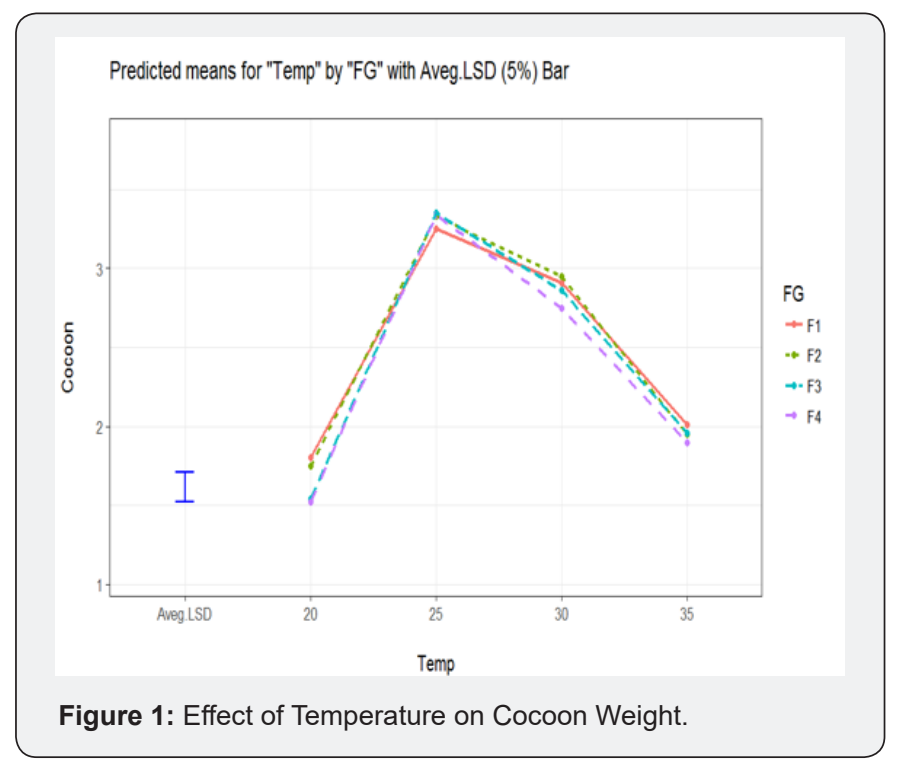

Table 1: Mean separation of cocoon weights in grams, egg numbers and related factors as affected by temperature.

\begin{tabular}{|c|c|c|c|c|}
\hline \multirow{2}{*}{$\begin{array}{l}\text { Sources of } \\
\text { Variation } \\
\text { (temp in } \\
\text { 0C) }\end{array}$} & \multicolumn{4}{|c|}{ Means } \\
\hline & Cocoon & Pupae & $\begin{array}{c}\text { Cocoon } \\
\text { Shell }\end{array}$ & $\begin{array}{c}\text { Egg } \\
\text { numbers }\end{array}$ \\
\hline 25 & $3.3175^{\mathrm{a}}$ & $2.9625^{\mathrm{a}}$ & $0.3550^{\mathrm{a}}$ & $395.65^{a}$ \\
\hline 30 & $2.8675^{\mathrm{b}}$ & $2.6025^{\mathrm{b}}$ & $0.2650^{\mathrm{b}}$ & $357.75^{b}$ \\
\hline 35 & $1.9550^{c}$ & $1.8075^{c}$ & $0.1475^{c}$ & $263.50^{c}$ \\
\hline 20 & $1.6525^{\mathrm{d}}$ & $1.5300^{\mathrm{d}}$ & $0.1225^{\mathrm{d}}$ & $203.00^{\mathrm{d}}$ \\
\hline $\mathrm{LSD}_{0.05}$ & 0.09316645 & 0.08868349 & 0.01912763 & 13.5582 \\
\hline
\end{tabular}

Table 1 shows the mean separation of the cocoon, pupae, cocoon shell, and egg numbers as affected by different temperature values. In all the cases, there were significant variations among the temperature test values and the highest responses were obtained when the rearing rooms were adjusted to $25{ }^{\circ} \mathrm{C}$. We also find the second optimal production of cocoon and related parameters when the rearing rooms have been adjusted at $30^{\circ} \mathrm{C}$. Thus, these two rearing temperature conditions are the best and optimal conditions for good quality cocoon production and silkworm seed cocoon selection.

As indicated in Table1, the maximum mean egg number was 395.65 when moths exposed to $25 \pm 2{ }^{\circ} \mathrm{C}$ temperature. The next higher mean number of eggs (356.75) was recorded when moths were grown at $30 \pm 2{ }^{\circ} \mathrm{C}$ room temperature.

The mean separation bar for effect of temperature on pupae production is shown in Figure 2 \& Table 1. In the graph (Figure 2 ), it is obvious that the first two groups of temperature had a significant improvement on pupae production than the other two group temperatures. Though there was a statistically significant variation between each temperature values, the most prominent performances were observed for T2 (25 degrees Celsius) and T3 (30 degree Celsius), indicting the most appropriate room temperatures for production of pupae and thereby cocoons.

\section{Groups and Range}

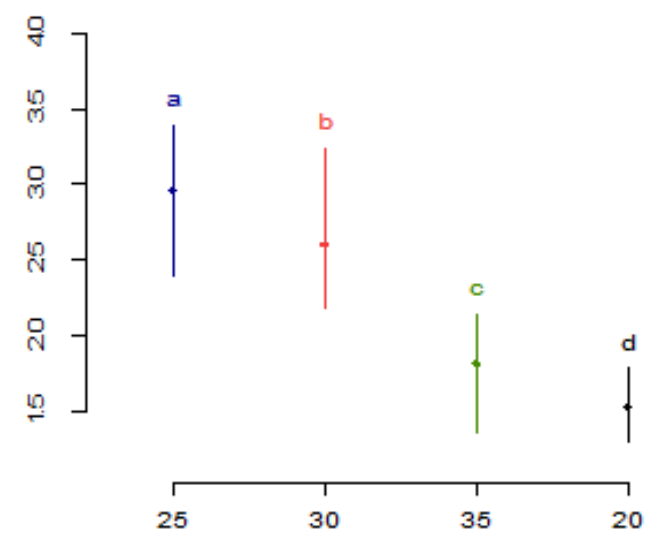

Figure 2: LSD for temperature using pupae as response variable

Pupae weight was significantly $(\mathrm{P}<0.001)$ affected by the temperature gradients (Table 2). The maximum pupae weight was obtained when the rearing rooms were adjusted to 25 degree centigrade (Figure 3). When adjusting the rearing rooms to higher or lower temperature ranges, weight of silkworm's pupae significantly reduced. Filial generations significantly affected this pupae weight, especially the F3 and F4 filial generations ( $\mathrm{P}$ $<0.05$ ). This difference also revealed in interaction between the temperature gradients and the filial generations which had effect on the pupae weight of especially the F3 and F4. Furthermore, as indicated in table1, the highest mean pupae weight was $2.96 \mathrm{~g}$ at $25 \pm 2{ }^{\circ} \mathrm{C}$ temperature. As a result, one can infer that optimum ranges of temperature for both healthy seed and cocoon production are 25 and $32^{\circ} \mathrm{C}$. 


\section{Agricultural Research \& Technology: Open Access Journal}

Table 2: Analysis of Variance on cocoon parameter.

\begin{tabular}{|c|c|c|c|c|c|c|}
\hline Response & Sources of Variation & Df & Sum Sq & Mean Sq & F value & $\operatorname{Pr}(>\mathrm{F})$ \\
\hline \multirow{5}{*}{ Cocoon } & Rep & 9 & 0.57 & 0.06 & 1.4256 & 0.183 \\
\hline & Temp & 3 & 72.32 & 24.11 & 543.1 & $<2 \mathrm{e}-16^{* * *}$ \\
\hline & FG & 3 & 0.38 & 0.13 & 2.88 & $0.03844^{*}$ \\
\hline & Temp: FG & 9 & 0.58 & 0.06 & 1.45 & 0.17218 \\
\hline & Residuals & 135 & 5.99 & 0.04 & & \\
\hline \multirow{5}{*}{ Pupae } & Rep & 9 & 0.48 & 0.053 & 1.32 & 0.23455 \\
\hline & Temp & 3 & 53.75 & 17.92 & 445.51 & $<2 \mathrm{e}-16^{* * *}$ \\
\hline & FG & 3 & 0.27 & 0.09 & 2.29 & 0.08883 \\
\hline & Temp: FG & 9 & 0.48 & 0.05 & 1.32 & 0.23383 \\
\hline & Residuals & 135 & 5.43 & 0.04 & & \\
\hline \multirow{5}{*}{ Cocoon Shell } & Rep & 9 & 0.016 & 0.0018 & 0.98 & 0.463 \\
\hline & Temp & 3 & 1.399 & 0.466 & 249.35 & $<2.2 \mathrm{e}-16^{* * *}$ \\
\hline & FG & 3 & 0.024 & 0.0078 & 4.19 & 0.0072 \\
\hline & Temp: FG & 9 & 0.026 & 0.0029 & 1.54 & 0.139 \\
\hline & Residuals & 135 & 0.253 & 0.0019 & & \\
\hline \multirow{5}{*}{ Egg } & Rep & 9 & 8852 & 984 & 1.0463 & 0.40685 \\
\hline & Temp & 3 & 925049 & 308350 & 328.0401 & $<2 \mathrm{e}-16^{* * *}$ \\
\hline & FG & 3 & 6213 & 2071 & 2.2034 & 0.09057 \\
\hline & Temp: FG & 9 & 8119 & 902 & 0.9597 & 0.47626 \\
\hline & Residuals & 135 & 126897 & 940 & & \\
\hline \multirow{5}{*}{ Egg Hatched } & Rep & 9 & 6593 & 733 & 0.7711 & 0.6433 \\
\hline & Temp & 3 & 1224073 & 408024 & 429.4702 & $<2 \mathrm{e}-16^{* * *}$ \\
\hline & FG & 3 & 1803 & 601 & 6324 & 0.5953 \\
\hline & Temp: FG & 9 & 8903 & 989 & 1.0412 & 0.4108 \\
\hline & Residuals & 135 & 128259 & 950 & & \\
\hline \multirow{5}{*}{ Hatchability } & Rep & 9 & 156.9 & 17.4 & 0.6011 & 0.7943 \\
\hline & Temp & 3 & 13737.5 & 4579.2 & 157.854 & $<2 \mathrm{e}-16^{* * *}$ \\
\hline & $\mathrm{FG}$ & 3 & 79 & 26.3 & 0.9077 & 0.4392 \\
\hline & Temp: FG & 9 & 259.7 & 28.9 & 0.9946 & 0.4476 \\
\hline & Residuals & 135 & 3916.2 & 29 & & \\
\hline
\end{tabular}

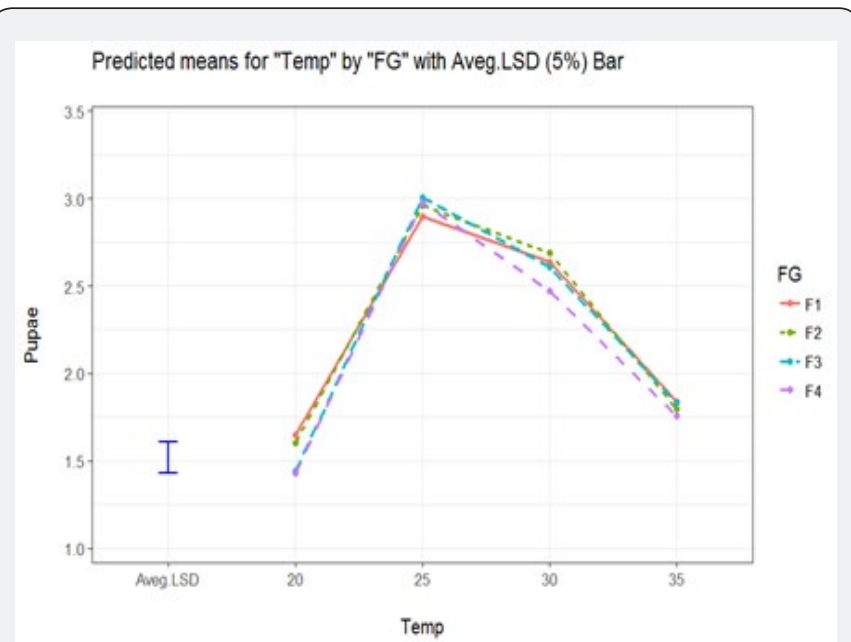

Figure 3: LSD for temperature using pupae as response variable.

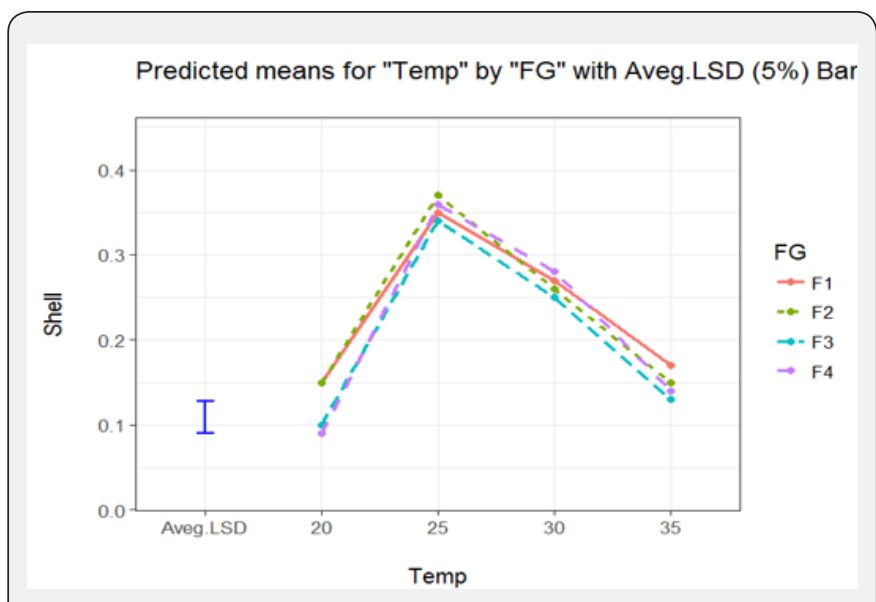

Figure 4: LSD for temperature using shell as response variable.

The maximum single mean cocoon shell weight was recorded at temperature $25^{\circ} \mathrm{C}(0.355 \mathrm{~g})$. Whereas, the lowest meant cocoon 
weight $(0.1225 \mathrm{~g})$ was obtained at $20^{\circ} \mathrm{C}$. Thus, one can infer that lower temperature has an influence on required shell weight of the cocoon (Figure 4). The maximum number of eggs laid per moth laying was obtained when the rearing rooms were adjusted to 25 degree centigrade (Figure 5).

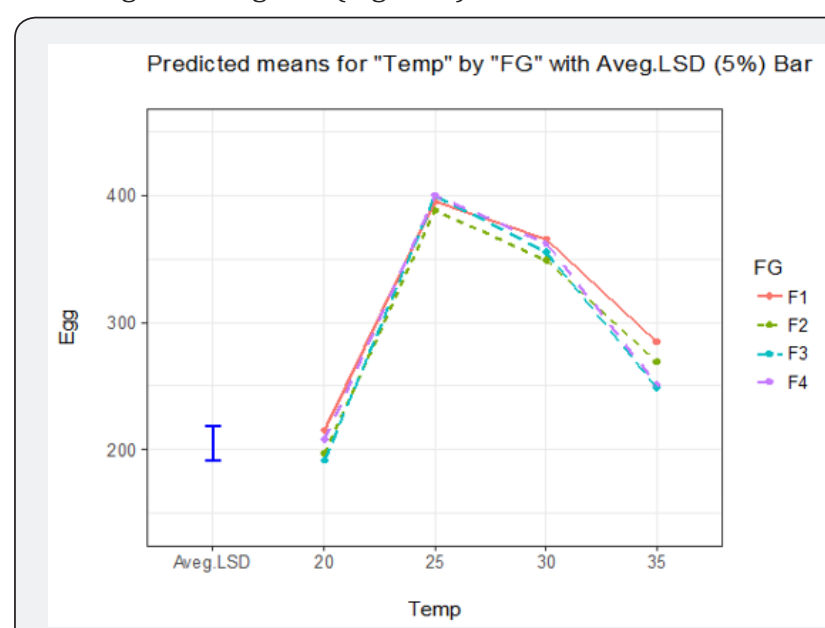

Figure 5: LSD for temperature using egg as response variable.

Number of eggs was significantly $(\mathrm{P}<0.001)$ affected by the temperature gradients (Table 2). Similarly, egg number and hatchability were influenced by the temperature. None of these parameters was affected by filial generations, except cocoon weight.

\section{Discussion}

Temperature variations affected growth and production of Eri silkworms. Earlier studies else where also indicated that the optimum temperature for better growth and higher cocoon yield ranged between $23{ }^{\circ} \mathrm{C}$ to $28{ }^{\circ} \mathrm{C}[7,11,14]$; temperature above 30 ${ }^{\circ} \mathrm{C}$ and below $20^{\circ} \mathrm{C}$ markedly affect performance of the worms, particularly in early stages; as a result, worms become too weak and easily exposed to various diseases. However, multivoltine breeds reared in tropical countries are known to tolerate higher temperature and adjust with tropical climatic conditions $[14,11,16]$. While temperature above $35^{\circ} \mathrm{C}$ has an adverse effect on growth of eri silkworm and then leads to loss of cocoon yield through death of larva [14]. These previous research findings were in line with present findings (Figure 1). Another study recommended even higher temperature of up to $40^{\circ} \mathrm{C}$ [12]. Consequently, current study reflects that it is necessary to monitor the temperature and relative humidity of the rearing rooms and maintain them around room temperature and $75 \pm 5 \%$ relative humidity. The area where this experiment was carried out have annual average temperature ranges from $23{ }^{\circ} \mathrm{C}$ to $30.57{ }^{\circ} \mathrm{C}$ [13], with the highest temperature value $33.5^{\circ} \mathrm{C}$ measured during February in 2017 and the lowest temperature value $19{ }^{\circ} \mathrm{C}$ measured during October in 2016. Thus, it is crucial to apply different mechanisms to maintain relative humidity and temperature during these extreme periods.

Cocoon production was also found to be slightly affected by the filial generations of the silkworms and no difference was observed between first and second filial generations. This contradicts earlier experimental results which reported that cocoon yields of eri silkworm were obtained regularly from early generation until 12th generation which allowed directional selection at $42 \pm 1$ ${ }^{\circ} \mathrm{C}$ and low humidity (50 $\pm 5 \%$ R.H.) [14]. Hence, we infer that temperature plays critical role on the growth of the silkworms and their yield parameters regardless of filial generations. This might be due to silkworms being cold-blooded animals and hence their physiological activities are highly susceptible to fluctuation of temperature in rearing room $[7,17]$. Similarly, our experimental results showed that filial generations also had no significant effect on pupae, egg production and hatchability. We suspect that marinating newly hatched eggs in refrigerator may reduce their potential and result in non-significant difference among the filial generations. Therefore, it is essential to adjust desired temperature for each stage.

Fluctuation of temperature in rearing room result in low cocoon shell weight. Thus, it is crucial to maintain $25^{\circ} \mathrm{C} \pm 2{ }^{\circ} \mathrm{C}$ temperature in the rearing room in order to obtain better cocoon shell weight. This result was in line with research findings which states that any temperature outside range of $22{ }^{\circ} \mathrm{C}-25^{\circ} \mathrm{C}$ during spinning process of Bombyx mori results in poor cocoon shell parameters that shell becomes very loose and folded with wrinkles and knots [11,17].

Egg production and hatchability were highly influenced by the temperature variations. The optimal range of temperature $23{ }^{\circ} \mathrm{C}-30{ }^{\circ} \mathrm{C}$ was important for good egg production in the study area. Temperature values above or below these levels should be monitored and adjusted to nearly room temperature values. Similar findings were reported by other researchers validating our results $[9,11,18]$. Temperatures above $30^{\circ} \mathrm{C}$ and abnormal cold treatment of embryos might also cause embryonic death or abnormal development. Furthermore, one particular research that conducted in western Maharashtra, India depicted that maintaining room temperature at $28 \pm 2{ }^{\circ} \mathrm{C}, 8 \pm 5 \% \mathrm{RH}$ and $10 \mathrm{hrs}$ photo period during egg incubation results in successful hatching percentage, larval duration, larval weight, cocoon yield, single cocoon weight, shell weight, shell ratio, etc $[17,19]$. Thus, cocoon production for both quality yield and seed purpose primarily relies on optimum conditions of temperature and humidity management during all life cycles.

\section{Conclusion}

Eri silkworm is one of poikilothermic animals which cannot adjust its physiological processes against variations in the ambient temperature. Therefore it is crucial to set an optimum temperature to harvest both potential yield of cocoon and quality seed cocoon production. Hence, the ideal temperature for improved eri silwkorm cocoon and seed production, in the rearing room of eri silkworm ranges from 25 to $30^{\circ} \mathrm{C}$. However, further study will be appropriate to investigate local temperature and humidity requirements for cocoon and seed production by smallholder Eri silkworm farmers in the study area.

\section{Acknowledgement}

We acknowledge the generous support of Bere Sericulture 
Production PLC in allowing its facilities for the conduct of this experiment. The lead author is also grateful to the YESH Project team of ICIPE for various technical assistances and encouragement during the course of producing this study.

\section{Conflict of Interest}

The authors declare that there is no conflict of interest in the conduct of this experiment and publication of the findings.

\section{References}

1. Ahmed I, Abiy T, Metasebiya T, Kedir S (2017) Feed consumption rate and feeding frequencies of Eri and Mulberry silkworm at Melkassa Agricultural Research Center, Ethiopia. Acad Res J Agri Sci Res 5(1): 20-26.

2. Oduor OE, Ciera L, Adolka V, Pido O (2016) Eri Silkworm Rearing Practices in Kenya: Technical University of Kenya Nairobi, Kenya. JEZS 4(5): 197-201.

3. Zhang Y, Geleta H, Endale H (2017) Present Situation and Countermeasures of Sericulture Development in Ethiopia. J Silk (54)11: 50-55.

4. Affognon H, Diiro G, Liuliseged B, Shifa B (2014) Rapid Appraisal of Value Chains of Honey Beekeeping in Bure District and Silk Farming in Arba Minch District in Ethiopia. International Centre of Insect Physiology and Ecology (ICIPE), Addis Ababa, Ethiopia.

5. Longvah T, Manghtya K, Qadri SS (2012) Eri silkworm: a source of edible oil with a high content of $\alpha$-linolenic acid and of significant nutritional value. J Sci Food Agric 92(9): 1988-1993.

6. Kedir S, Emana G, Waktole S (2016) Leaf mineral composition of castor genotypes and its relationship with productivity of eri silkworms (Samia Cynthia ricini B.) IJER 1(4): 10-15.

7. Renuka G, Shamitha G (2014) Studies on the economic traits of Eri silkworm, Samia cynthia ricini, in relation to seasonal variations. International Journal of Advanced Research 2(2): 315-322.

8. Gezahegn T, Metaferia H, Kedir S, Nobuaki Y (2005) Sericulture Training Guide. JICA Addis Ababa, Ethiopia. p: 43.

9. Batham R, Yadav U (2015) Effect of Mating Duration on Fecundity (Reproductive Parameter) of Eri Silk Moth Philosamia ricini in Different Seasons. IJR Granthaalaya 3(9): 1-3.

10. Sarmah MC, Sarkar BN, Ahmed SA (n date) Course Ware: Eri Culture. Central Muga Eri Research \& Training Institute, Central Silk Board, Ministry of Textiles, Govt. of India, Lahdoigarh-785700, Jorhat, Assam. p: 43.

11. Rahmathulla VK (2012) Management of Climatic Factors for Successful Silkworm (Bombyx mori L.) Crop and Higher Silk Production: A Review.
Journal Hindawi 2012: 1-12.

12. Brahma D (2015) Effect of Rearing Seasons on the Economic Parameters of Cross breed Silkworm between Samia ricini and Samia canningi. Int J Pharm Bio Sci 6(4): 875-881.

13. Gezahagn A (2017) Long term climate data description in Ethiopia. 14:371-392.

14. Wongsorn D, Sirimungkararat S, Saksirirat W (2015) Improvement of Eri Silkworm (Samia ricini D.) Tolerant to High Temperature and Low Humidity Conditions by Continuously Regime. J Sci Technol 37(4): 401-408.

15. Rajan RK, Himantharaj MT (2005) Silkworm Rearing Technology. Central Silk Board, Bangalore, India. p: 5-136.

16. Imtiyaz Rasool Parrey, Yasir AL (2018) Impact of Temperature on Crop and Higher Silk Production: Silkworm (Bombyx mori L.) MOJ Food Process Technol 6(2): 186-187.

17. Sisodia NS, Gaherwal S (2017) Effects of temperature and relative humidity on commercial product of silkworm (Bombyx mori L) in India. International Journal of Zoology Studies 2(5):52-55.

18. Mubashar H, Muhammad N, Shakil AK, Muhammad FB, Muhammad $M$ (2011) Studies on the influence of temperature and humidity on biological traits of silkworm (Bombyx mori L.; Bombycidae). African J Biotechnol 10(57): 12368-12375.

19. Rangrao K (2015) Terminalia Arjuna - A new host of Philosamia ricini eri silkworm under Western Maharashtra condition. Int J Pharm Bio Sci 6(1): 787-792. 
- Quality Editorial service

- Swift Peer Review

- Reprints availability

- E-prints Service

- Manuscript Podcast for convenient understanding

- Global attainment for your research

- Manuscript accessibility in different formats

( Pdf, E-pub, Full Text, Audio)

- Unceasing customer service

Track the below URL for one-step submission https://juniperpublishers.com/online-submission.php 